\title{
Characterization of oxygen defect and zinc segregation in the dense tin dioxide ceramics added with zinc oxide
}

\author{
Isao SAKAGUCHI, ${ }^{\dagger}$ Naoya SAKAMOTO,${ }^{*}$ Minako HASHIGUCHI, ${ }^{* *,}$, \\ Hisayoshi YURIMOTO, ${ }^{* *}$ Shunichi HISHITA and Naoki OHASHI \\ National Institute for Materials Science (NIMS), 1-1 Namiki, Tsukuba, Ibaraki 305-0044, Japan \\ *Isotope Imaging Laboratory, Creative Research Institution, Hokkaido University, Sapporo 001-0021, Japan \\ ${ }^{* *}$ Natural History Sciences, Hokkaido University, Sapporo 060-0810, Japan
}

\begin{abstract}
We investigated the effect of zinc oxide addition for the defects in the dense $\mathrm{SnO}_{2}$ ceramics. Cathode and photoluminescence properties revealed the luminescence originated to oxygen vacancies in $\mathrm{SnO}_{2}$ grains and the presence of non-radiative defect at the grain boundaries. The oxygen diffusion profile showed that the oxygen diffusion was controlled by the limited process at the surface and uniform concentration of ${ }^{18} \mathrm{O}$ at the grain boundaries inner side of sample. This sample exhibited a low $\mathrm{Zn}$ concentration in grains and a high $\mathrm{Zn}$ concentration at grain boundaries. We conclude that segregation of $\mathrm{Zn}$ at grain boundaries prevents $\mathrm{SnO}_{2}$ from decomposing at high temperatures, enabling dense $\mathrm{SnO}_{2}$ ceramics to be obtained.

(C)2013 The Ceramic Society of Japan. All rights reserved.
\end{abstract}

Key-words : Oxygen vacancy, Segregation, $\mathrm{SnO}_{2}$, Secondary ion mass spectrometry

[Received May 10, 2013; Accepted September 12, 2013]

\section{Introduction}

Tin oxide $\left(\mathrm{SnO}_{2}\right)$ is an n-type semiconductor with a wide band gap $\left(E_{\mathrm{g}}=3.6 \mathrm{eV}\right)$. It has been extensively studied for use in solar cells and gas sensors and as an oxidation catalyst. ${ }^{1)-3)}$ While $\mathrm{SnO}_{2}$ in gas sensors in the form of thin films and porous nanosized $\mathrm{SnO}_{2}$ were extensively studied and proposed the conduction mechanism, ${ }^{3)}$ dense $\mathrm{SnO}_{2}$ ceramics have been little investigated because they are difficult to fabricate. The lack of bulk $\mathrm{SnO}_{2}$ forms such as dense ceramics and single crystals has hindered research on the physicochemical properties of $\mathrm{SnO}_{2}$. It is generally difficult to produce dense $\mathrm{SnO}_{2}$ ceramics without employing additives because $\mathrm{SnO}_{2}$ decomposes and its constituents evaporate during sintering.

Jarzebski and Marton ${ }^{4)}$ reviewed research prior to 1976 on preparing $\mathrm{SnO}_{2}$ and its defect chemistry. Van Daal ${ }^{5)}$ grew polycrystalline $\mathrm{SnO}_{2}$ by vapor transport and realized a bulk density of $95 \%$. Samson and Fonstad ${ }^{6}$ found that doubly ionized oxygen vacancies predominate in $\mathrm{SnO}_{2}$ for partial oxygen pressures between $10^{-2}$ and 1 atmosphere and in the temperature range 700 $1330^{\circ} \mathrm{C}$. Their findings strongly imply that when $\mathrm{SnO}_{2}$ ceramics are sintered above $1200^{\circ} \mathrm{C}$, oxygen vacancies are introduced into $\mathrm{SnO}_{2}$ grains by the decomposition reaction. Quadir and Readey ${ }^{7)}$ found that sintering $\mathrm{SnO}_{2}$ in an $\mathrm{H}_{2}$ atmosphere improved its compactness and reduced its apparent density. Moreover, $\mathrm{SnO}_{2}$ decomposed and condensed at temperatures above $1200^{\circ} \mathrm{C}$. It is thus critical to suppress decomposition and evaporation at high temperatures to produce dense $\mathrm{SnO}_{2}$ ceramics. Park et al. ${ }^{8)}$ synthesized dense $\mathrm{SnO}_{2}$ ceramics without additives at a high temperature and a high pressure. Another way to synthesize dense $\mathrm{SnO}_{2}$ ceramics is to use additives. Useful additives for $\mathrm{SnO}_{2}$

† Corresponding author: I. Sakaguchi; E-mail: SAKAGUCHI.Isao@ nims.go.jp

* Present address: National Institute for Materials Science (NIMS), 1-1 Namiki, Tsukuba, Ibaraki 305-0044, Japan are $\mathrm{MnO}_{2},{ }^{9)} \mathrm{CoO},{ }^{9), 10)} \mathrm{CuO},{ }^{11)} \mathrm{ZnO},{ }^{12)-17)} \mathrm{Nb}_{2} \mathrm{O}_{5},{ }^{18)} \mathrm{Sb}_{2} \mathrm{O}_{3},{ }^{19)}$ $\mathrm{In}_{2} \mathrm{O}_{3}{ }^{20)}$ and $\mathrm{Bi}_{2} \mathrm{O}_{3} .{ }^{21)}$ These additives have larger ionic sizes and different charge states from $\mathrm{Sn}$ in the host material. Additives that improve sintering of other oxides have a low solubility limit and tend to segregate to grain boundaries. ${ }^{22)}$ The formation of a secondary phase in ceramics reduces the additive concentration in host grains.

Of the additives that have been used to fabricate dense $\mathrm{SnO}_{2}$ ceramics, $\mathrm{ZnO}$ is an important semiconductor due to its potential application in transparent devices and gas sensors made from $\mathrm{SnO}_{2}$. Matthews and Kohnke ${ }^{12)}$ found that $\mathrm{ZnO}$ addition produced dense $\mathrm{SnO}_{2}$ ceramics. A densification model for $\mathrm{SnO}_{2}$ ceramics with $\mathrm{ZnO}$ addition has been discussed in terms of oxygen vacancy formation. ${ }^{14), 16)}$ Perazolli et al. ${ }^{14)}$ proposed that enhanced oxygen diffusivity is the key cause for densification of $\mathrm{SnO}_{2}$ ceramics on $\mathrm{ZnO}$ addition. Foschini et al. ${ }^{16)}$ suggested that $\mathrm{ZnSnO}_{3}$ precipitates at grain boundaries in samples with $\mathrm{ZnO}$ contents over $1 \mathrm{~mol} . \%$ and acts as a barrier that prevents grain boundary motion and inhibits densification. Using transmission electron microscopy/energy-dispersive spectroscopy, they found a secondary phase at triple junctions, but did not observe $\mathrm{Zn}$ segregation at grain boundaries. In the system of $\mathrm{ZnO}-\mathrm{SnO}_{2}, \mathrm{Zn}_{2} \mathrm{SnO}_{4}$ and $\mathrm{ZnSnO}_{3}$ are possible precipitate phases. ${ }^{23), 24)}$ Palmer and Poeppelmeier ${ }^{25)}$ studied the phase relation of the $\mathrm{Ga}_{2} \mathrm{O}_{3}-\mathrm{SnO}_{2}-\mathrm{ZnO}$ system. They reported that the solubility limit of $\mathrm{Zn}$ in $\mathrm{SnO}_{2}$ was less than $0.7 \%$. $\mathrm{Zn}$ is incorporated in $\mathrm{SnO}_{2}$ grains only at relatively low concentrations when $\mathrm{SnO}_{2}$ is sintered at a high temperature of $1400^{\circ} \mathrm{C}, \mathrm{ZnO}$ has a high vapor pressure.

Oxygen vacancy in $\mathrm{SnO}_{2}$ has been investigated by optical methods such as photoluminescence (PL) and cathodoluminescence (CL) measurements. Such measurements revealed that oxygen vacancies in $\mathrm{SnO}_{2}$ generate deep level luminescence of the peak at $1.94 \mathrm{eV}$ (wavelength: $640 \mathrm{~nm}$ ). ${ }^{26), 27)}$ Another method to evaluate the oxygen vacancy, self-diffusion experiments provided further direct evidence of oxygen vacancies in $\mathrm{SnO}_{2}$. For example, oxygen isotope diffusion can be used to directly 
determine the relation between oxygen vacancies and dopants in oxide semiconductors. ${ }^{28)}$ Oxygen diffusion in $\mathrm{SnO}_{2}$ has been used to investigate the kinetics processes of sensors. ${ }^{29}$ )

The present study focuses on dense $\mathrm{SnO}_{2}$ ceramics produced by $\mathrm{ZnO}$ addition because the $\mathrm{ZnO}-\mathrm{SnO}_{2}$ system is expected to give transparent ceramics. CL and PL measurements were used to detect oxygen vacancies in $\mathrm{ZnO}$ doped $\mathrm{SnO}_{2}$ ceramics. Oxygen tracer diffusion and zinc distribution in $\mathrm{ZnO}$ doped $\mathrm{SnO}_{2}$ ceramics were investigated by ion beam techniques such as secondary ion mass spectrometry (SIMS) to find ways to improve the sinterability of $\mathrm{SnO}_{2}$ ceramics. Direct measurements of oxygen diffusion using ${ }^{18} \mathrm{O}$ tracers are suitable for investigating the chemistry of oxygen defects in $\mathrm{SnO}_{2}$. Finally, we propose a model for the formation of dense $\mathrm{SnO}_{2}$ ceramics by $\mathrm{ZnO}$ addition.

\section{Experimental methods}

Dense $\mathrm{SnO}_{2}$ ceramics were prepared by conventional sintering technique. The reagent-grade powders of $\mathrm{SnO}_{2}$ and $\mathrm{ZnO}$ (HighPurity Chemicals Ltd.) were used as the starting materials. From previous studies, $\mathrm{X}$-ray powder diffraction analyses indicated that $\mathrm{ZnO}-\mathrm{SnO}_{2}$ secondary phases were not present in $\mathrm{SnO}_{2}$ ceramics with a $\mathrm{ZnO}$ concentration of below about $5 \mathrm{~mol} . \% .^{14)-16)}$ Since these results indicate that it is possible to fabricate dense $\mathrm{SnO}_{2}$ that does not contain secondary phases. Consequently, we selected $\mathrm{ZnO}$ concentration of $0.25 \mathrm{~mol} \%$ in the present study, from the preliminary experiments to fabricate the dense $\mathrm{SnO}_{2}$ ceramics added with $\mathrm{ZnO}$. The powders were mixed by ball milling (YTZ-3) in ethanol for $20 \mathrm{~h}$. After drying, the powders were pressed into disks (diameter: $10 \mathrm{~mm}$; thickness: $3 \mathrm{~mm}$ ). These disks were sintered at $1440^{\circ} \mathrm{C}$ for $2 \mathrm{~h}$ in air. The sintered disks were polished and finished with several grades of diamond pastes. After the sample surfaces had been mirror finished, they were washed with ethanol. The samples were annealed at $1000^{\circ} \mathrm{C}$ for $30 \mathrm{~min}$ in air, to remove the polishing damages. The $\mathrm{ZnO}$ doped $\mathrm{SnO}_{2}$ ceramics $\left(\mathrm{Zn}-\mathrm{SnO}_{2}\right)$ with the relative density of $91 \%$ were used as the substrate.

$\mathrm{Zn}-\mathrm{SnO}_{2}$ ceramics were characterized by photoluminescence, PL, (Accent Technology Co. Ltd., RPM-2000; $\lambda=266 \mathrm{~nm}$ ). The following measurements were performed. Their microstructures were evaluated by scanning electron microscopy (SEM; JEOL, JSM-7000F) equipped with a cathode luminescence, CL, detector (Gatan, Mini CL). SEM and CL images were obtained by using a focused electron beam (acceleration voltage: $15 \mathrm{kV}$ ).

$\mathrm{Zn}-\mathrm{SnO}_{2}$ ceramics were used to evaluate diffusion of ${ }^{18} \mathrm{O}_{2}$ gas (95\% purity). The sample was loaded into an exchange system to achieve ${ }^{18} \mathrm{O}$ diffusion. This was then annealed at $1000^{\circ} \mathrm{C}$ for $3 \mathrm{~h}$. The oxygen tracer diffusion profiles and $\mathrm{Zn}$ distribution in $\mathrm{SnO}_{2}$ ceramics were measured by SIMS (Cameca, IMS-6f and IMS1270 at Hokkaido university). In the measurement of oxygen tracer concentration profiles, the ${ }^{16} \mathrm{O}$ and ${ }^{18} \mathrm{O}$ intensities were measured as a function of time. After analysis, the SIMS crater depth was measured using a laser scanning microscope (Keyence, VK-9710; wavelength: $408 \mathrm{~nm}$ ). The obtained depth profiles were converted to ${ }^{18} \mathrm{O}$ concentration profiles using the following equation: $C_{(x, t)}\left[{ }^{18} \mathrm{O}\right]=\mathrm{I}\left[{ }^{18} \mathrm{O}\right] /\left[\left[\mathrm{I}^{16} \mathrm{O}\right]+\mathrm{I}\left[{ }^{18} \mathrm{O}\right]\right]$, where $\mathrm{C}\left[{ }^{18} \mathrm{O}\right]$ and $\mathrm{I}\left[{ }^{18} \mathrm{O}\right]$ are the ${ }^{18} \mathrm{O}$ concentration and the ${ }^{18} \mathrm{O}$ intensity. Moreover, direct ion images of ${ }^{16} \mathrm{O}^{-},{ }^{18} \mathrm{O}^{-},(\mathrm{ZnO})^{-}$, and $(\mathrm{SnO})^{-}$in $\mathrm{SnO}_{2}$ ceramics were obtained using IMS-1270 equipped with a highefficiency stacked CMOS active pixel sensor for charged particles. ${ }^{30)}$ This instrument can directly measure ion images with high signal-to-noise ratios in the high-resolution mode of a mass spectrometer because the lateral resolution of ion images is independent of the primary ion beam size. The signal ratio of $\mathrm{ZnO}$ and $\mathrm{SnO}$ negative ions was converted into the $\mathrm{ZnO}$ concentration using the inner standard produced by $\mathrm{Zn}$ ion implantation.

\section{Results and discussion}

Figure 1 shows the results of microstructure by SEM and optical properties by CL measurements. The SEM image in Fig. 1(a) reveals that the sample is dense and contains grains with diameters in the range $2-10 \mu \mathrm{m}$. The CL image in Fig. 1(b) indicates the distribution of radiative and non-radiative defects in the sample. Figures 1(a) and 1(b) reveal that CL signal is emitted from grains, but not near grain boundaries. These are evident of the different state around the defect.

Figure 2 shows PL spectrum of the $\mathrm{SnO}_{2}$ sample. Sample contains a simple peak at a wavelength of $640 \mathrm{~nm}$. Orange luminescence at a wavelength of $640 \mathrm{~nm}$ was observed in a previous study and it was assigned to oxygen vacancies, $V_{O}^{\bullet \bullet}$, in $\mathrm{SnO}_{2}{ }^{27}$ ) From Fig. 1(b), the $\mathrm{SnO}_{2}$ grains contain oxygen vacancy as the radiative defect. On the other, it seems that oxygen vacancy as the non-radiative defect presents near the grain boundaries.

Figure 3 shows oxygen diffusion profile obtained for $\mathrm{Zn}-$ $\mathrm{SnO}_{2}$ annealed at $1000^{\circ} \mathrm{C}$ for $3 \mathrm{~h}$. It has an ${ }^{18} \mathrm{O}$ surface concentration of 0.09 , which is considerably smaller than that for ${ }^{18} \mathrm{O}_{2}$ gas, indicating that the surface reaction became a limited process in the experiment and $\mathrm{O}$ isotopic exchange is dominant at grain boundaries. The oxygen bulk diffusion coefficient was estimated roughly to be $2 \times 10^{-16} \mathrm{~cm}^{2} / \mathrm{s}^{31)}$ A high-resolution image of ${ }^{18} \mathrm{O}$ was obtained in the tail region, and result shows the inset of Fig. 3. The grain boundaries exhibited a constant intensity of ${ }^{18} \mathrm{O}$. The grain boundary diffusion coefficient could not be determined because selective sputtering during SIMS measurements.

Figure 4 shows a high-resolution concentration map and line analysis of the $\mathrm{SnO}_{2}$ ceramics. Figure 4(a) shows a concentration
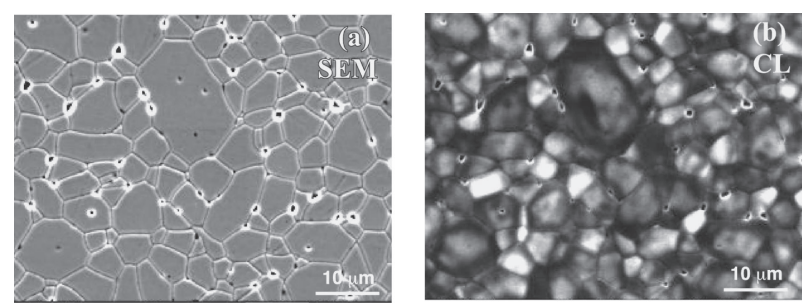

Fig. 1. Microstructure and optical property of $\mathrm{Zn}-\mathrm{SnO}_{2}$. (a) SEM image and (b) CL image.

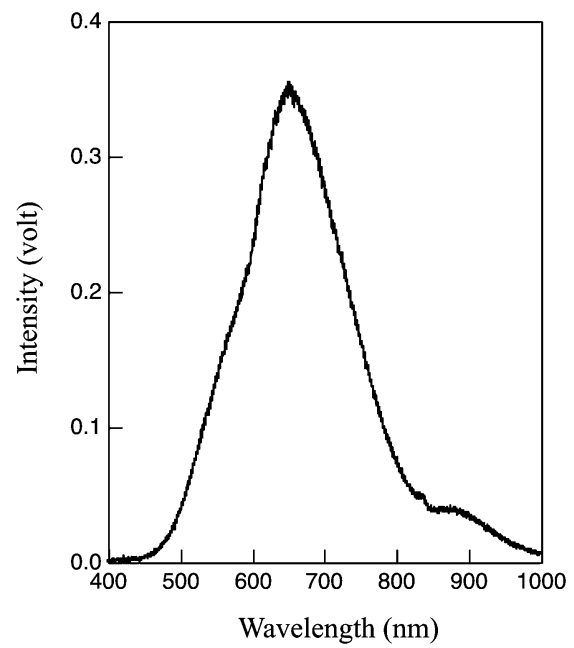

Fig. 2. Photoluminescence spectrum obtained in $\mathrm{Zn}-\mathrm{SnO}_{2}$ sample. 
image of $(\mathrm{ZnO})^{-}$in which $\mathrm{Zn}$ segregates at all grain boundaries. The $\mathrm{Zn}$ concentration in this image varies at grain boundaries. The $\mathrm{Zn}$ concentration in $\mathrm{SnO}_{2}$ grain is enough small rather than that of grain boundary segregation. Some particles with high $\mathrm{Zn}$ concentration were found at the triple junctions and grain boundaries. These were secondary phase related with $\mathrm{Zn}-\mathrm{SnO}_{2}$. Figure 4(b) shows the results of line analysis between the line I-II in Fig. 4(a). The grain boundaries of $\mathrm{SnO}_{2}$ grains have Zn concentrations of about $3 \times 10^{18}$ and $1.4 \times 10^{19} / \mathrm{cm}^{3}$ in this figure. The above results indicate a considerably low $\mathrm{Zn}$ concentration in $\mathrm{SnO}_{2}$ grains and grain boundary segregation of $\mathrm{Zn}$. These findings suggest that $\mathrm{Zn}$ segregation at the grain boundaries is a critical phenomenon for densification of $\mathrm{SnO}_{2}$ ceramics.

Our results in Figs. 1(b) and 2 indicate that the defect, oxygen vacancy, is different state in the grains and the grain boundaries. So, we discuss by separating the oxygen defect in grain and at the grain boundaries. On the oxygen defect in the grains, the oxygen defect such as vacancy acts as the radiative defect [Figs. 1(b) and 2]. The oxygen defect formation relates with the sintering process. Quadir and Readey ${ }^{7}$ studied sintering of $\mathrm{SnO}_{2}$ in a hydrogen atmosphere. They found that $\mathrm{SnO}_{2}$ disks expanded due to agglomerate growth of grains due to evaporation and condensation above $1200^{\circ} \mathrm{C}$. The process can be expressed by

$$
\mathrm{SnO}_{2} \rightarrow \mathrm{Sn}_{\mathrm{Sn}}^{\times}+\mathrm{O}_{\mathrm{O}}^{\times}+\mathrm{V}_{\mathrm{O}}^{\times}\left(\mathrm{V}_{\mathrm{O}}^{\bullet \bullet}+2 e^{\prime}\right)+1 / 2 \mathrm{O}_{2}(\uparrow) .
$$

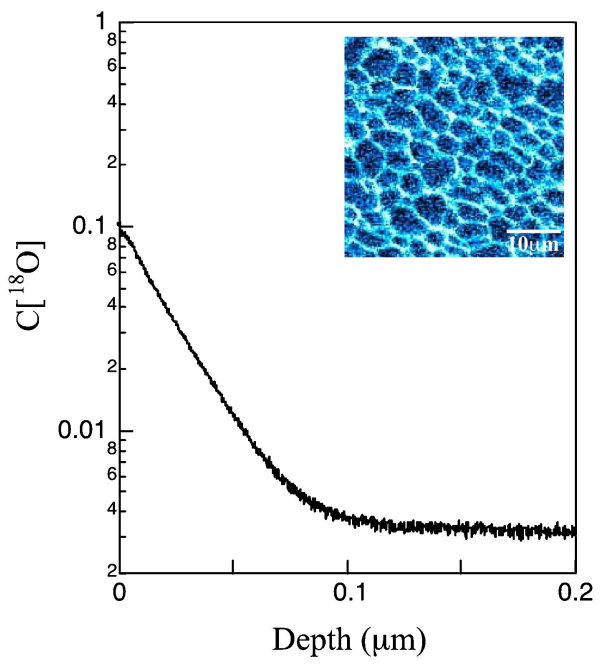

Fig. 3. ${ }^{18} \mathrm{O}$ diffusion profile obtained for $\mathrm{Zn}-\mathrm{SnO}_{2}$. The inset shows an ${ }^{18} \mathrm{O}$ ion image at the depth of $400 \mathrm{~nm}$.
$\mathrm{SnO}_{2}$ behaves n-type conduction, if parts of Vo state as the charged vacancy. Another possible equation to form the defects in $\mathrm{SnO}_{2}$ lattice is considered as the partial decomposition of $\mathrm{SnO}_{2}$. For example, the reaction is written as

$$
2 \mathrm{SnO}_{2} \rightarrow \mathrm{Sn}_{\mathrm{Sn}}^{\times}+\mathrm{V}_{\mathrm{Sn}}^{\times}+3 \mathrm{O}_{\mathrm{O}}^{\times}+\mathrm{V}_{\mathrm{O}}^{\times}+\mathrm{SnO}(\uparrow) .
$$

As described in the above, two possible equations are considered to decompose $\mathrm{SnO}_{2}$. In order to improve the sinterability, several sintering aids have been used to produce dense $\mathrm{SnO}_{2}$ ceramics. The sinterability of $\mathrm{SnO}_{2}$ can be improved by using these aids based on the supposed enhancement in the oxygen diffusivity. Perazolli et al. ${ }^{14)}$ and Foschini et al. ${ }^{16)}$ gave the following equation for incorporation:

$$
\mathrm{ZnO} \rightarrow \mathrm{Zn}_{\mathrm{Sn}}^{\prime \prime}+\mathrm{V}_{\mathrm{O}}^{\bullet \bullet}+\mathrm{O}_{\mathrm{O}}^{\times}
$$

The $\mathrm{Zn}$ concentration of $3 \times 10^{18} / \mathrm{cm}^{3}$ in $\mathrm{SnO}_{2}$ grain in Fig. 4 is enough small rather than the added concentration. If above reaction is a dominant reaction, it is expected that its effect is found in the oxygen diffusion feature. Diffusion profile in Fig. 3 shows that oxygen diffusion is limited by the exchange reaction between ${ }^{18} \mathrm{O}_{2}$ and $\mathrm{O}$ at the surface. This reflects the lack of charge in sample and the exchange reaction depended on the atmosphere $^{32)}$ and temperature. Result in Fig. 3 was obtained from the diffusion experiment at $1000^{\circ} \mathrm{C}$, because $\mathrm{SnO}_{2}$ causes the decomposition and evaporation at high temperature. At this time, it is difficult to understand that diffusion phenomenon reflects the $\mathrm{Zn}$ incorporation in $\mathrm{SnO}_{2}$. So, we conclude that the origin of oxygen vacancy in $\mathrm{SnO}_{2}$ grain is mainly described by Eqs. $(1,2)$.

On the oxygen defect at the grain boundaries, our results in Fig. 1(b) indicated that the defect presented as the non-radiative defect. The uniform intensity of ${ }^{18} \mathrm{O}$ at the grain boundary was observed in Fig. 3. This is the evidence that the grain boundary diffusion was independent of the grain boundary structure. Moreover, it was found $\mathrm{Zn}$ segregation at the grain boundaries in Fig. 4. Here, two possible models were considered the incorporation of $\mathrm{Zn}$ near the grain boundary in $\mathrm{SnO}_{2}$ and the formation of grain boundary phase by $\mathrm{Zn}$ segregation. First model is assumed the $\mathrm{Zn}$ diffusion into $\mathrm{SnO}_{2}$ grains. The amount of oxygen vacancy near the grain boundary increases by the $\mathrm{Zn}$ incorporation reaction of Eq. (3). From first model, the weak CL intensity near the grain boundaries in Fig. 1(b) seems to be explained such as the increase of oxygen vacancy and/or the formation of complex defect of $\left(Z n_{S n}^{\prime \prime}-V_{O}^{\bullet \bullet}\right)^{\times}$from the charge neutrality. However, the feature of oxygen grain-boundary diffusion, which is the uniform intensity of ${ }^{18} \mathrm{O}$ in Fig. 3, is not explained by first model. Second model is the formation of secondary phase at the
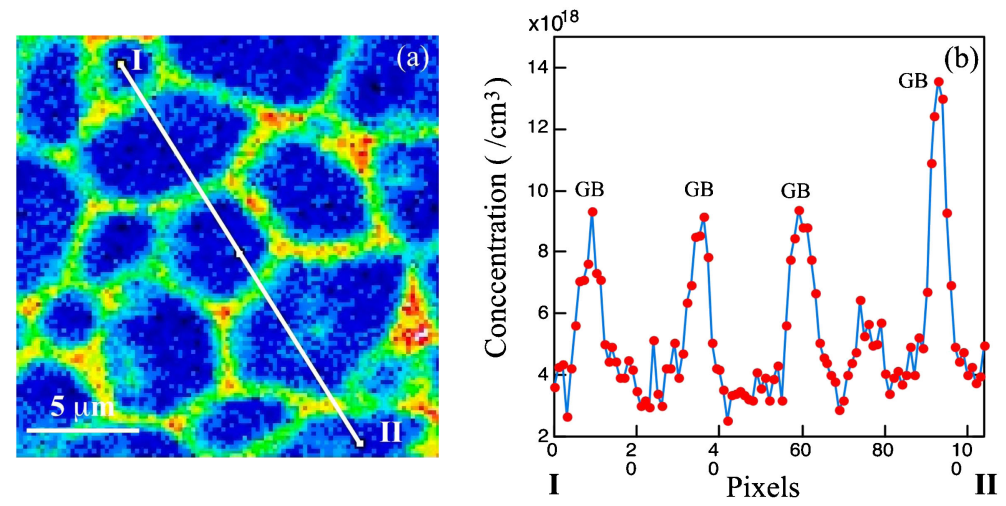

Fig. 4. High-resolution ion image (a) and line analysis (b) of $\mathrm{Zn}$ for $\mathrm{Zn}-\mathrm{SnO}_{2}$. (a) high-resolution $\mathrm{Zn}$ image and (b) line analysis along I-II in Fig. 4(a). GB in Fig. 4(b) shows the grain boundary. 
grain boundaries during the sintering. Previous studies reported the secondary phase of $\mathrm{Zn}_{2} \mathrm{SnO}_{4}$ spinel at triple junction in $\mathrm{SnO}_{2}$ ceramics added with the large amount of $\mathrm{ZnO}$ using TEM technique, but not detected $\mathrm{Zn}$ segregation and secondary phase at the grain boundaries. Hashemi et al. ${ }^{33)}$ proposed that sintering to produce $\mathrm{Zn}_{2} \mathrm{SnO}_{4}$ ceramics could be controlled by the diffusion-evaporation mechanism of $\mathrm{ZnO}$ that gave rise to a higher $\mathrm{Zn}$ concentration at the walls of inner pores in $\mathrm{Zn}_{2} \mathrm{SnO}_{4}$ ceramics. A similar phenomenon between sintering and the additive was found for transparent alumina $\left(\mathrm{Al}_{2} \mathrm{O}_{3}\right)$ ceramics fabricated by $\mathrm{MgO}$ addition. ${ }^{34)}$ In this case, $\mathrm{Mg}$ segregation at the grain boundaries suppressed abnormal grain growth. Approach from oxygen diffusion study revealed the uniform oxygen diffusivity at the grain boundaries of alumina by $\mathrm{Mg}$ segregation at the grain boundaries. ${ }^{35)}$ Consequently, transparent alumina ceramics results from the good sinterability were produced. In this study, similar results were found such as the oxygen grainboundary diffusion independent of the grain boundary structure in Fig. 3 and $\mathrm{Zn}$ segregation at the grain boundary in Fig. 4. From the analogy, it seems that the secondary phase with $\mathrm{ZnO}$ and $\mathrm{SnO}_{2}$ compositions at the grain boundary is formed during the sintering and $\mathrm{SnO}_{2}$ grains are covered with the secondary phase. As a result, the $\mathrm{Zn}$ segregated grain boundaries suppress the decomposition and evaporation of $\mathrm{SnO}_{2}$ described by Eqs. $(1,2)$, and cause the uniform oxygen transport along the grain boundaries. Finally, the dense $\mathrm{SnO}_{2}$ ceramics are synthesized.

\section{Conclusions}

We have fabricated the dense $\mathrm{SnO}_{2}$ ceramics added with $\mathrm{ZnO}$ of $0.25 \mathrm{~mol} . \%$ to study the optical property, oxygen tracer diffusion, and elemental distribution. The following findings were obtained:

1) SEM image shows that $\mathrm{Zn}-\mathrm{SnO}_{2}$ ceramics is dense. CL image reveal that radiative and non-radiative oxygen vacancies are concentrated in grains and grain boundaries, respectively. PL measurements gave a simple spectra with a peak centered at a wavelength of about $640 \mathrm{~nm}$, which was assigned to oxygen vacancies.

2) Oxygen diffusion using ${ }^{18} \mathrm{O}$ indicates that the diffusion is controlled by the surface reaction. Additionally, the uniform intensity of ${ }^{18} \mathrm{O}$ was observed at the grain boundaries.

3) The $\mathrm{Zn}$ distribution in dense $\mathrm{SnO}_{2}$ ceramics was measured by using SIMS loaded with a SCAPS. The Zn concentration in $\mathrm{SnO}_{2}$ grains is considerably smaller than the added $\mathrm{Zn}$ concentration. $\mathrm{Zn}$ segregation was observed at grain boundaries.

4) The change in the physicochemical properties of $\mathrm{SnO}_{2}$ induced by $\mathrm{Zn}$ segregation at the grain boundaries gave insight into the densification of $\mathrm{SnO}_{2}$ ceramics. The densification of $\mathrm{SnO}_{2}$ ceramics by $\mathrm{ZnO}$ addition is due to the $\mathrm{Zn}$-rich grain boundaries formed by $\mathrm{Zn}$ diffusion and evaporation acting as barriers to suppressing decomposition and condensation of $\mathrm{SnO}_{2}$. Consequently, dense $\mathrm{SnO}_{2}$ ceramics are fabricated.

\section{References}

1) J. F. Wagner, Science, 300, 1245-1246 (2003).

2) D. E. Williams, Sens. Actuators, B, 57, 1-16 (1999).

3) N. Barsan and U. Weimar, J. Electroceram., 7, 143-147 (2001).

4) Z. M. Jarzebski and J. P. Marton, J. Electrochem. Soc., 123, 199C-205C (1976)
5) H. J. Van Daal, Solid State Commun., 6, 5-9 (1968).

6) S. Samson and C. G. Fonstad, J. Appl. Phys., 44, 4618-4621 (1973).

7) T. Quadir and D. W. Readey, in G. C. Kuczynsdi, A. E. Miller, G. A. Sargent (Ed.) Microstructure Evolution in $\mathrm{SnO}_{2}$ and $\mathrm{CdO}$ in Reducing Atmosphere in Sintering and Heterogeneous Catalysis, Plenum Publ. Co. (1984) p. 159.

8) S. J. Park, K. Hirota and H. Yamamura, Ceram. Int., 10, 115116 (1984).

9) J. A. Cerri, E. R. Leite, D. Gouvea and E. Longo, J. Am. Ceram. Soc., 79, 799-804 (1996).

10) J. A. Varela, J. A. Cerri, E. R. Leite, E. Longo, M. Shamsuzzoha and R. C. Bradt, Ceram. Int., 25, 253-256 (1999).

11) S. A. Pianaro, P. R. Bueno, E. Longo and J. A. Varela, J. Mater Sci. Lett., 14, 692-694 (1995).

12) H. E. Matthews and E. E. Kohnke, J. Phys. Chem. Solids, 29, 653-661 (1968).

13) L. T. Grigoryan, Z. H. Gedakyan and K. A. Kostanyau, Inorg. Mater., 12, 313 (1974).

14) L. Perazolli, C. R. Foschini, T. R. Giraldi, R. S. Biscaro, J. A. Varela and E. Longo, Sintering Sci. Technol., 12, 117-122 (2000).

15) L. Perazolli, A. Z. Simons, U. Coleto, Jr., F. Moura Filho, S. Gutierrez, C. O. P. Satons, J. A. G. Carrio, R. F. C. Marques and J. A. Varela, Mater. Lett., 59, 1859-1865 (2005).

16) C. R. Foschini, L. Perazolli and V. A. Varela, J. Mater. Sci., 39, 5825-5830 (2004).

17) J. Liu and W. Ning, J. Mater. Sci., 44, 2520-2524 (2009).

18) J. Takahashi, I. Yamai and H. Saito, Yogyo Kyokai-shi, 83, 362-366 (1975).

19) Y. H. Yu, H. H. Zhang and H. M. Yang, J. Alloys Compd., 453, 292-297 (2008).

20) G. Z. Zang, J. F. Wang, H. C. Chen, W. B. Su, W. X. Wang, C. M. Wang and P. Qi, J. Non-Cryst. Solids, 351, 941-945 (2005).

21) M. Muraoka, M. Suzuki, Y. Sawada and J. Matsushita, J. Mater. Sci., 33, 5621-5624 (1998).

22) I. Sakaguchi, H. Haneda, J. Tanaka and T. Yanagitani, J. Am. Ceram. Soc., 79, 1627-1632 (1996).

23) D. L. Young, D. L. Williamson and T. J. Coults, J. Appl. Phys., 91, 1464-1471 (2002).

24) I. Stambolova, A. Toneva, V. Blaslov, D. Radev, Y. Tsevtanova, S. Vassilev and P. Peshev, J. Alloys Compd., 391, L1-L4 (2005).

25) G. B. Palmer and K. R. Poeppelmeier, Solid State Sci., 4, 317322 (2002).

26) D. Maestre, A. Cremades and J. Piqueras, J. Appl. Phys., 97, 044316 (2005).

27) D. Maestre, A. Cremades and J. Piqueras, J. Cryst. Growth, 311, 1212-1216 (2009).

28) I. Sakaguchi, K. Watanabe, Y. Adachi, T. Ohgaki, S. Hishita, N. Ohashi and H. Haneda, Jpn. J. Appl. Phys., 50, 125501 (2011).

29) B. Kamp, R. Merkle and J. Maier, Sens. Actuators, B, 77, 534542 (2001).

30) H. Yurimoto, K. Nagashima and T. Kunihiro, Appl. Surf. Sci., 203-204, 793-797 (2003).

31) J. Crank, The Mathematics of Diffusion. Oxford University Press, London, U.K. (1967).

32) J. Liu, R. J. Chater, R. J. H. Morris and S. J. Skinner, Solid State Ionics, 189, 39-44 (2011).

33) T. Hashemi, H. M. Al-Allak, J. Illingsworth, A. W. Brinkman and J. Woods, J. Mater. Sci. Lett., 9, 776-778 (1990).

34) H. I. Marcus and M. E. Fine, J. Am. Ceram. Soc., 55, 568-570 (1972).

35) I. Sakaguchi, V. Srikanth, T. Ikegami and H. Haneda, J. Am. Ceram. Soc., 78, 2557-2560 (1995). 